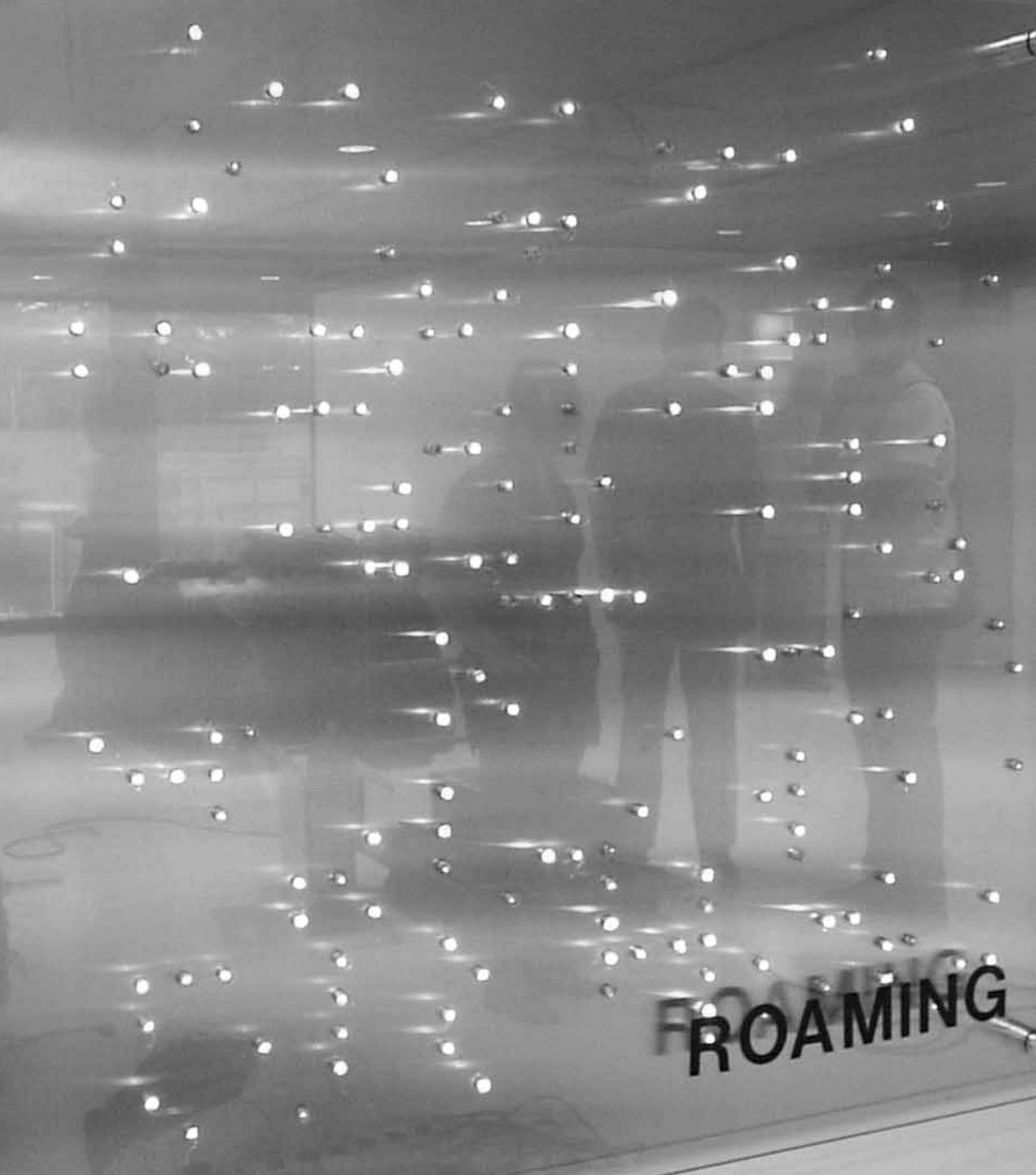




\section{Intromissão e invisibilidade em experimentações artísticas com radiação eletromagnética}

\section{FABIO FON}

SORAYA BRAZ

Resumo

Como uma necessidade de explorar as tecnologias de seu tempo, diversas produções artísticas em novos meios irão discutir o universo dos dispositivos móveis e suas conseqüências no âmbito social. Roaming e Grampo, de Fabio Fon e Soraya Braz, são trabalhos que se inserem dentro deste universo, explicitando também a presença invisível da radiação eletromagnética. $\mathrm{O}$ presente artigo tem como propósito expor o contexto social e tecnológico, os conceitos e o processo criativo envolvidos na produção das experimentações em questão. 


\section{Abstract}

As a need to explore the technologies of their time, various artistic productions in new media will discuss the universe of mobile devices and their consequences in the social scope. Roaming and Grampo, by Fabio FON and Soraya Braz, are artworks introduced to this universe, also explaining the invisible presence of electromagnetic radiation. Moreover, the present article has the purpose of exposing the technological and social context, the concepts and the creative process involved in the production of the experiments in question. 


\section{Intromissão}

A ubiqüidade dos telefones celulares em nossa sociedade contemporânea implica em uma série de condutas sociais e implicações conseqüentes de seu uso. Falar ao telefone celular de assuntos pessoais em voz alta, apropriando-se de local público, pode ser a base para muitas discussões sobre privacidade. Algumas podem ser bem irônicas, como a do estúdio de design Coudal Partners em Chicago, EUA, que desenvolveu vários "cartões de visitas" sob a assinatura da SHHH! Society for HandHeld Hushing ${ }^{1}$ (algo como Sociedade para calar portáteis), com o propósito de alertar polidamente (ou não) os falantes de que sua conversa ao celular está perturbando o entorno e ninguém está interessado nela. Um dos cartões, que dispõe até de um espaço para completar com o tema da conversa, é apresentado da seguinte forma: "Caro usuário de telefone celular: Nós estamos cientes que a sua conversa sobre 'a vasectomia de seu marido' [inscrição na área a completar] é muito importante para você, mas, nós pensamos que você deveria saber que isso não nos interessa de modo algum. De fato, sua tagarelice indiferente aos outros é mais do que um mero aborrecimento". Em outros modelos, há cartões com situações mais comuns a serem assinaladas: “...nós estamos cientes de que a sua conversa com: () seu amigo () sua amiga () sua mãe () seu terapeuta, sobre: () a noite de ontem () sobre o jogo () sobre 'ele' () sobre 'ela' é muito importante para você..., explicitando ainda a previsibilidade daquelas conversas. A intenção é que estes cartões sejam entregues aos falantes, causando um inevitável constrangimento. Experiências como esta explicitam os comportamentos envolvidos no uso de telefones celulares.

Diversas produções em arte e tecnologia irão discutir o universo dos dispositivos móveis e suas conseqüências no âmbito social, como resultado da necessidade de explorar as tecnologias de seu tempo, muitas vezes, as subvertendo, alcançando reflexões e posturas críticas. Não por acaso, o desdobramento desta nova cultura de mobilidade atraiu a atenção de artistas que perceberam no telefone celular uma poderosa interface criativa. "Um indicativo importante de que a tecnologia está se tornando ubíqua acontece quando a arte começa a lidar com esses aparelhos, desafiando seus limites e funções estabelecidas" (DE SOUZA E SILVA, 2004, p.277). De acordo com a artista Giselle Beiguelman, a respeito da popularidade dos dispositivos móveis sem fio, estes indicam "a incorporação do padrão de vida nômade e indicam que o corpo humano se transforma, rapidamente, em um conjunto de exten-
1. Material disponível em http:// www.coudal.com/shhh.php. Acesso em 1o de abril de 2009 . 
sões ligadas a um mundo cíbrido, pautado pela interconexão de redes e sistemas on e off line." (BEIGUELMAN, 2005, p. 160)

Em 2003, o artista Crispin Jones junto a IDEO, uma empresa britânica de desenho industrial, desenvolveu "celulares-conceito" chamados Social Mobiles. São cinco tipos diferentes de aparelhos que, de acordo com o artista, pretendem por maneiras diversas, diminuir os comportamentos perturbadores de seus usuários. Não foram desenvolvidos para o mercado de consumo, mas antes, para discutir o impacto social dos telefones celulares. O primeiro, chamado de SoMo 1, é o "celular do choque elétrico": ele descarrega uma corrente elétrica que varia a intensidade de acordo com a altura da voz da pessoa que está do outro lado da linha. Quanto mais barulhento, maior o choque. A troca mútua induz as duas partes a falarem mais baixo. Jones coloca que este telefone celular é feito para pessoas que insistem em conversar de maneira intrusiva. Temos também o SoMo 4 que remete a formas arcaicas de comunicação ao sugerir que o usuário simule uma seqüência de batidas na madeira como toque para chamadas urgentes. E há o SoMo 5 que é o aparelho celular que perturba a conversação de pessoas que falam intrusivamente em locais públicos. Basta apontar o aparelho para a pessoa tagarela e então o telefone daquele que incomoda emitirá sons irritantes, intrometendo-se no espaço do outro. Os aparelhos discutem o uso dos telefones celulares em locais públicos e suas conseqüências, gerando uma crítica em torno dessas circunstâncias. Cada vez mais, os celulares permanecem presentes em todos os espaços de presença humana, despertando a necessidade de pensar as conseqüências e condições apresentadas.

Aliás, pensando a respeito da ubiqüidade dos dispositivos móveis é interessante observar que a própria radiação eletromagnética oriunda da transmissão/recepção dos aparelhos celulares é um elemento que será igualmente onipresente neste tipo de comunicação nômade. No percurso artístico aqui apresentado, perceber esta onipresença será fundamental.

\section{Invisibilidade}

Bem, a radiação eletromagnética associada a uma permanente proximidade ao indivíduo tem sido vista com preocupação por alguns especialistas, já que o aparelho torna-nos diretamente expostos à radiação que ele emite. Não há um consenso científico em torno das possíveis conseqüências: ainda é discutível se 
o aparelho realmente pode proporcionar algum risco à saúde. $\mathrm{O}$ que certamente se sabe é que, muito ao contrário da radiação ionizante - denominação da radiação acima da freqüência da luz visível, utilizada nos Raios X -, a radiação não-ionizante - presente nos celulares e fornos microondas - não realiza alterações no DNA e não é prejudicial às células de modo imediato. Porém, diversos pesquisadores ainda têm dúvidas sobre o efeito cumulativo da absorção de radiação emitida pelos telefones celulares, como comprovadamente ocorre com a radiação do sol.

É evidente que uma conclusão afirmativa sobre o risco dos celulares não seria nada interessante para fabricantes e empresas envolvidas, resultando em prejuízos. No Brasil, há alguns pesquisadores como o cientista Vítor Baranauskas, professor da Universidade Estadual de Campinas, que defende que a radiação do celular causaria câncer, tumores benignos e cataratas, principalmente quando o sistema imunológico do usuário está debilitado. Já a Organização Mundial da Saúde (OMS), na condição de uma situação ainda não-conclusiva, defende cautela no uso do aparelho. O que é certo é que o questionamento pode vir a implicar em maiores explicações sobre essa tecnologia - tornando visível até onde os interesses financeiros de grandes grupos convergem com o interesse público - e em uma esfera maior, instiga à prática de ter posturas críticas para além destas circunstâncias.

No universo específico da radiação eletromagnética, o artista sonoro francês Julien Ottavi, participante do coletivo Apo33, realiza uma série de performances em espaços públicos de várias cidades pelo mundo, fazendo uso de um dispositivo específico um círculo metálico com pouco mais de $20 \mathrm{~cm}$ acompanhado de caixas acústicas - que explicita as emissões de radiação presentes nos espaços. O dispositivo emite ruídos eletrônicos em contato com equipamentos como aparelhos de ar condicionado, antenas, câmeras, televisores e telefones celulares. A intenção do trabalho é a experimentação sonora proveniente destas fontes, como uma incursão percursionista em acordes definidos ao acaso das ondas de radiação eletromagnéticas.

\section{Penduricalhos para telefones celulares}

Entre os muitos dispositivos criados com o intuito de personalizar ou decorar os aparelhos celulares, um especialmente chama atenção: trata-se um penduricalho que acende de modo febril quando um aparelho celular toca ou realiza ligações em 
proximidade. Os formatos destes "pisca-piscas para celular" são variados, trazendo de personagens inspirados em desenhos animados a figuras esotéricas. Estes dispositivos trazem em seu interior pequenos chips que detectam a presença da radiação eletromagnética emanada por aparelho próximo, acionando uma seqüência de luzes coloridas em LEDs dispostos sobre os diminutos aparelhinhos. Os chips, em sua maioria, são circulares e possuem um centímetro de diâmetro. Mas, o fato é que o badulaque, extremamente decorativo com suas luzes a ponto de remeterem a decorações natalinas, é capaz também de denunciar a presença invisível da radiação eletromagnética oriunda dos aparelhos celulares que o acompanham: certamente aí é possível desviar a futilidade do "pisca-pisca" e indicar outras leituras possíveis.

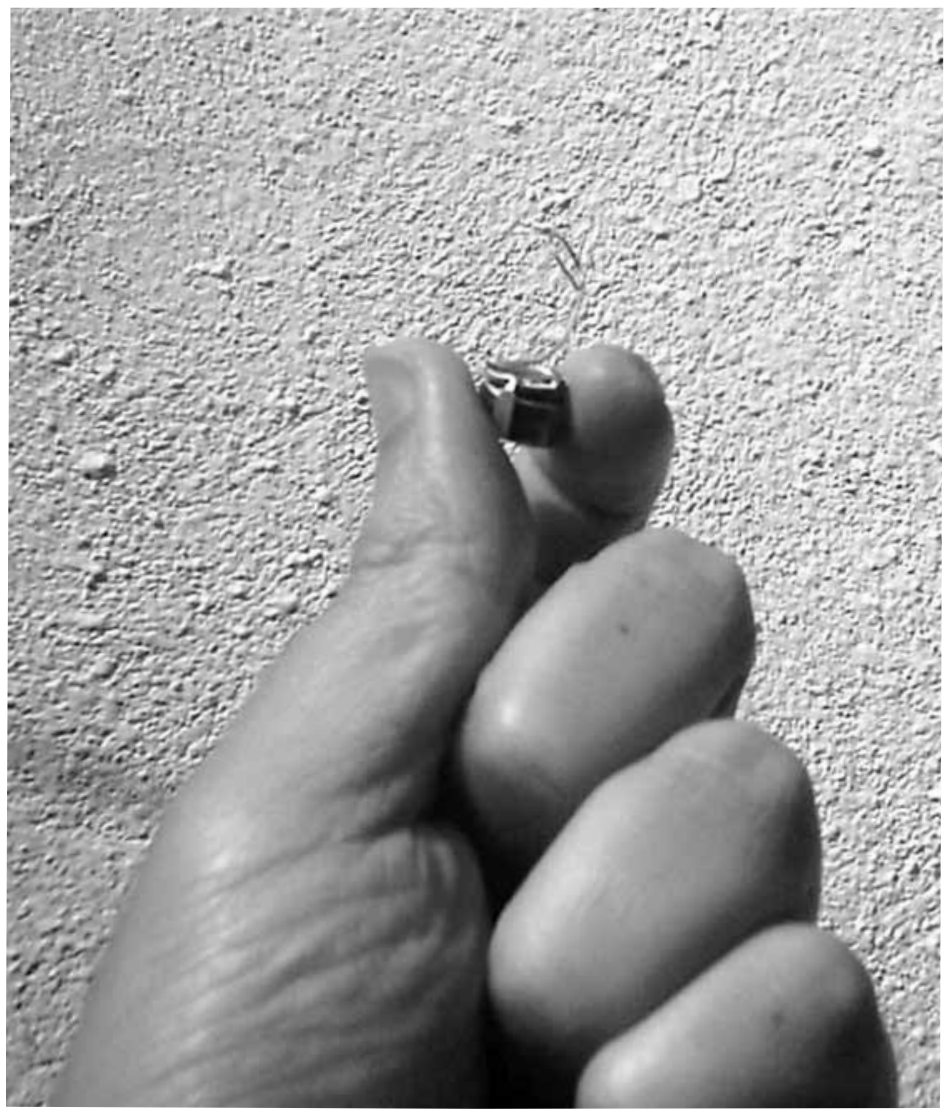

Figura o1 - Chip presente em penduricalhos para telefones celulares] 
Com a presença destes penduricalhos, em 2008, a artista brasileira Rosangella Leote realizou a tecnoperformance o80o-oooooo, apresentada na exposição EmMeio durante o $7^{\circ}$ Encontro de Internacional de Arte e Tecnologia, em Brasília, em que pedia ao espectador que ligasse de seu celular em um fictício número - a seqüência $0800-000000$-, no qual supostamente seria direcionado a um serviço de tele-atendimento. A consulta em questão estaria associada ao contexto da atividade de monitorias de eventos de Arte Ciência. Suscitando o universo de funcionalidades pífias da maioria dos serviços do gênero com suas práticas costumeiras como o gerundismo ${ }^{2}$ dos atendentes e a demorada espera para atendimento, a artista cria uma situação muito irônica e crítica de práticas obscuras viabilizadas com o uso do telefone. O tele-atendimento é um instrumento que tanto pode trazer comodidade ao usuário realizar remotamente suas consultas quanto pode ser uma barricada telemática, inserindo o usuário em uma lógica maquínica fundamentalmente impessoal.

Outro trabalho artístico que também faz uso dos mesmos penduricalhos é Cellphone Disco (2007). O trabalho dos artistas Auke Touwslager e Ursula Lavrencic consistiu em uma instalação dividida em duas partes: a primeira chamada "Mobile Aura" consiste na distribuição destes badulaques na intenção de tornar visível uma "aura" que envolve o aparelho celular durante seu uso; a segunda parte, chamada "Mobile Drawing" consiste em criar uma tela em que o celular deixa marcas de luz como um desenho eletromagnético. Em ambos os casos os autores pretendem revelar um "corpo invisível” da telefonia móvel, mas, no entanto, sem esboçar qualquer proposição crítica às questões aqui trazidas.

\section{Roaming}

Partindo de uma tentativa de desviar as intenções originais dos penduricalhos decorativos - desfazendo-se dos invólucros coloridos de personagens e outras figuras e, especialmente, desvelando seus chips - e ao mesmo tempo, estabelecendo um diálogo com a prática da apropriação artística, surgem alguns experimentos que originam o trabalho Roaming ${ }^{3}$, desenvolvido pelos artistas Fabio FON e Soraya Braz.

Inicialmente, ao adquirir várias unidades do badulaque "piscapisca", foram realizados testes para entender o funcionamento e os limites de sua possível utilização. O primeiro deles estava relacionado com a distância ideal de captação entre o telefone celular
2. Trata-se do uso sistemático dos verbos no gerúndio, muitas vezes soando como vício de linguagem em construções verbais como "vou estar telefonando" ou "vamos estar analisando".

3. Mais informações sobre o trabalho Roaming em: http:// www.fabiofon.com/roaming.html . Acesso em 20 de abril de 2009. 
e sensor, entre os diferentes tipos adquiridos. Abrindo estes penduricalhos, percebem-se algumas variações entre os componentes do sensor, como diferentes antenas e diferentes seqüências de luzes pré-determinadas. Nestes testes também se verificou que o sensor está mais apto a receber emissões de aparelhos celulares da banda B e C (na cidade de São Paulo) que correspondem a aparelhos que transmitem através da tecnologia GSM.

A maior preocupação durante o processo criativo foi pensar como relacionar o caráter decorativo e frívolo das pequenas peças com as preocupações conceituais e críticas levantadas. Optou-se pela justaposição de vários destes chips em uma composição fragmentada de nuances geométricos, criando uma superfície sensível e luminosa ao uso do celular em proximidade - emanando luz e explicitando o trânsito da radiação eletromagnética no ambiente. Da idéia de criar esta superfície, surge Roaming, um painel revestido de vidro com os sensores em seu interior que tornaria aparente e febril, o corpo invisível da radiação. $\mathrm{O}$ trabalho é um painel de $\mathrm{1m}^{2}$, constituído de duas lâminas sobrepostas, uma de alumínio (onde os sensores são fixados) e outra de vidro (que apresenta a palavra-título do trabalho em adesivo). Envidraçado e preso a uma parede, o trabalho reflete a imagem daqueles que observam e/ou participam do trabalho, inserindo-os na composição luminosa.

Em um dos cantos da lâmina de vidro está fixada a palavra-título Roaming que se refere ao termo empregado para determinar a transmissão de aparelhos de telefonia celular em locais distintos da sua região de origem. Embora o termo seja utilizado desta forma em língua portuguesa, a tradução da palavra significa, em inglês, viajando (termo que mais se aproxima do utilizado pelas empresas de telefonia), mas também pode significar andar a esmo ou vagar. Traz o sentido daquilo que não é próprio do local onde se encontra e que nos traz a incerteza de ser permanente. Bem, a configuração luminosa imprevisível - de alguns ou todos os sensores iluminados conforme a intensidade da transmissão é visível por alguns instantes e nos apresenta como vestígios transitórios da presença da radiação. É um índice da informação fluída dissipada em cada conversa ou mensagem enviada, que segue rumo a um conglomerado disforme de outras tantas atuações.

Então, podemos afirmar que Roaming, ao se iluminar, torna visível um corpo no qual o indivíduo contemporâneo está imerso: a presença cada vez ubíqua do ciberespaço. Estamos imersos den- 
tro desta trama informacional, onde as imagens da tevê, os sons do rádio ou os dados das redes flutuam silenciosamente no ar, perpassando nossas ruas, casas e corpos. O trabalho desvela um espectro silencioso e disforme que coabita hoje invisivelmente cada metro quadrado do planeta.

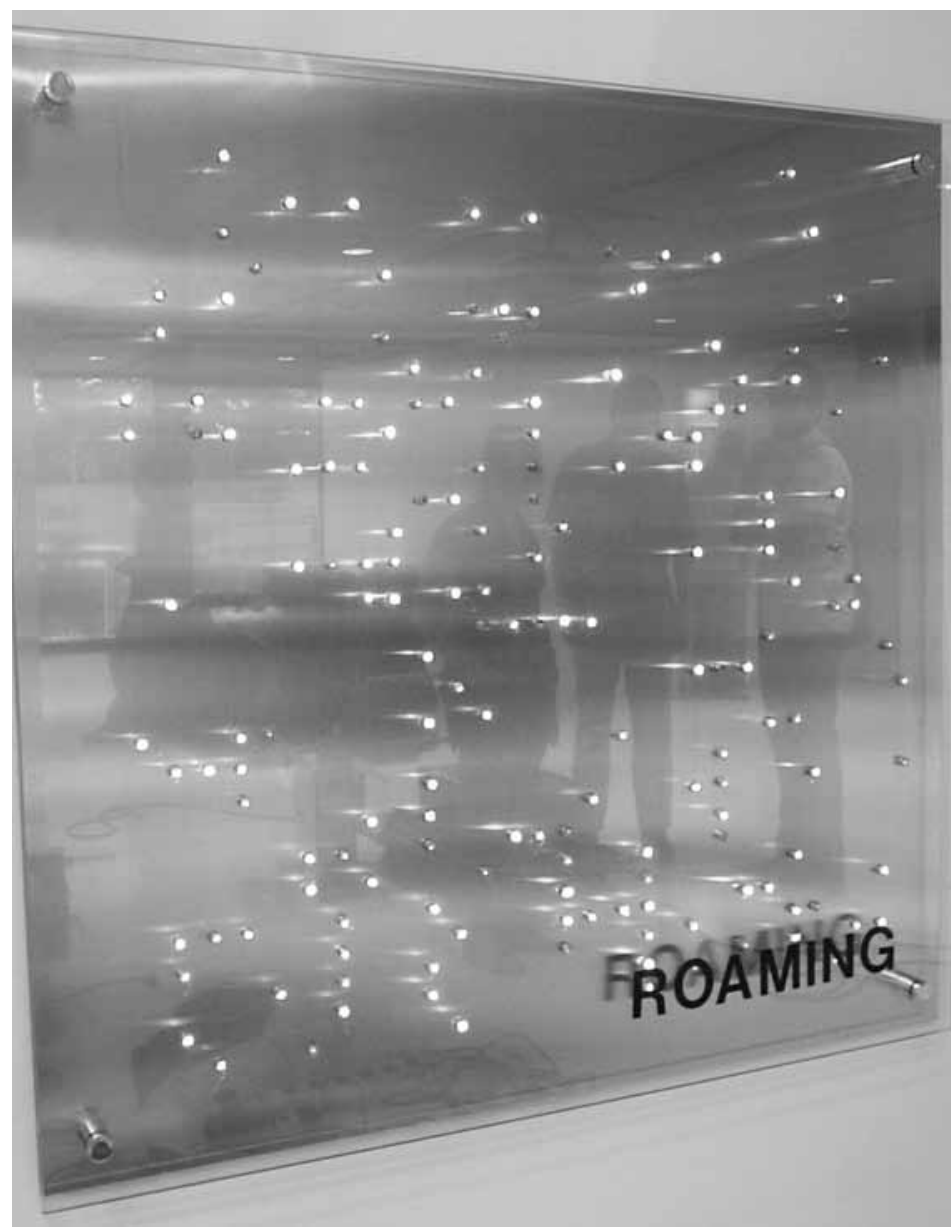

Figura o2 - Roaming de Fabio FON e Soraya Braz]

\section{Grampo}

Já um segundo trabalho que faz uso dos sensores é Grampo 4 , que possui uma maior complexidade de produção. Aqui, além da presença da radiação eletromagnética resultar em inúmeras seqüências luminosas de cada um dos sensores - os quais também estão distribuídos em grande quantidade sobre uma chapa de alumínio, como em Roaming -, há também uma outra
4. Mais informações sobre o trabalho Grampo em: http:// www.fabiofon.com/grampo.html . Acesso em 20 de abril de 2009. 
reação: o trabalho irá executar ruidosas conversas gravadas de pessoas utilizando celulares em espaços públicos. $\mathrm{O}$ modo com que os trechos de conversas foram capturados é o que dá nome ao trabalho: durante alguns meses antes da exibição do trabalho, os artistas mantiveram-se atentos às conversas mais pertubadoras nos espaços públicos que percorriam, como estações de metrô, trens, ônibus, shoppings, entre outros; todas estas conversas foram gravadas de modo dissimulado, sem o consentimento dos falantes intrusivos. As pessoas imersas no decorrer de suas conversas pouco percebem aquilo que se apresenta em seu redor - e não desconfiariam de um gravador similar a um $M p 3$ Player. Desta forma, as conversas são capturadas, tratadas com softwares de áudio e inseridas no banco de conversas presentes em Grampo.

Então, fazendo uso de uma placa Arduino ${ }^{5}$ para o gerenciamen-

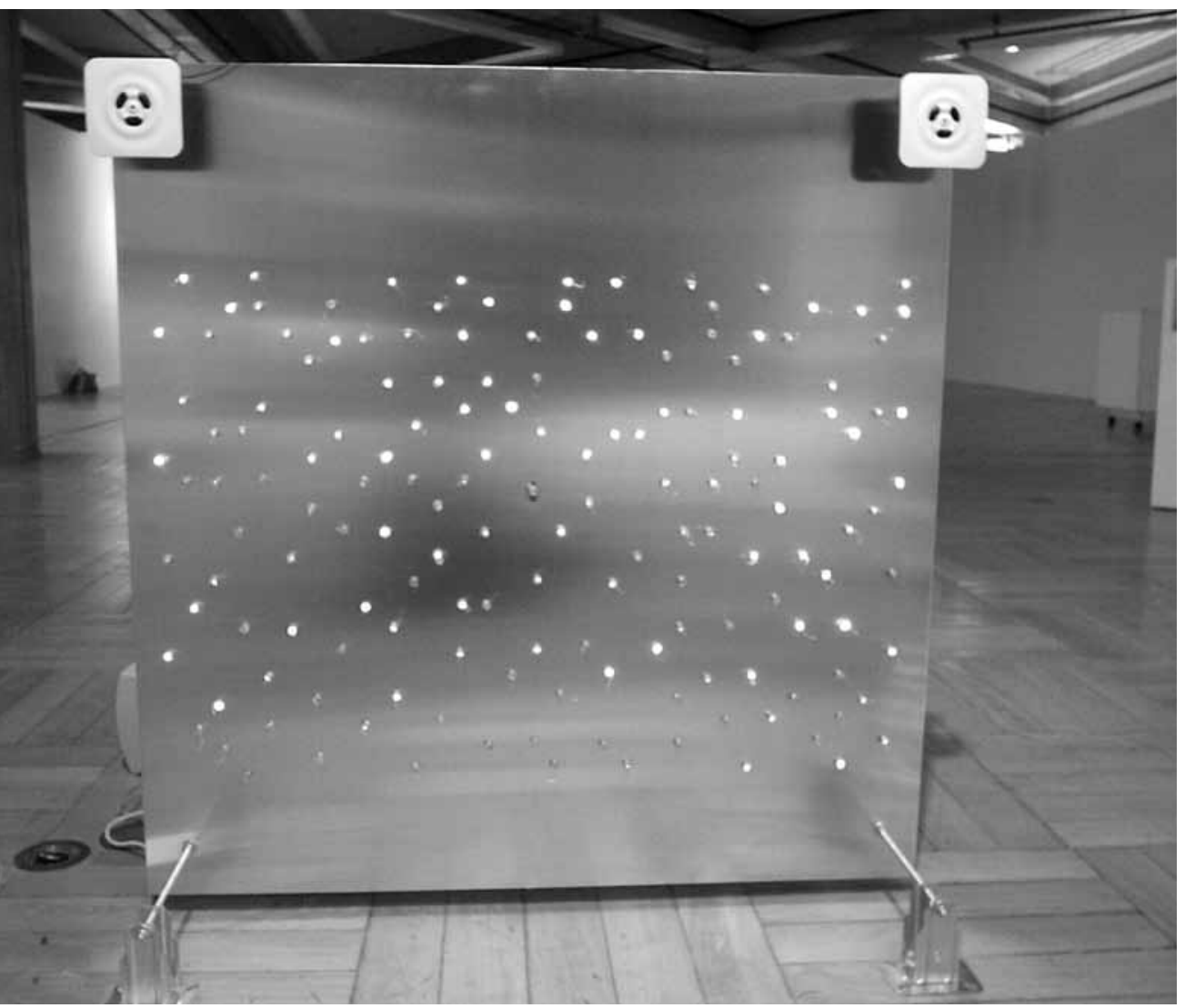

Figura o3 - Grampo de Fabio FON e Soraya Braz] 
to do sistema, a cada detecção de uso de celulares em proximidade, o trabalho não só reage com suas seqüências luminosas como também executa os sons dos usuários intrusivos durante alguns segundos. $\mathrm{O}$ sistema se resume na seguinte forma: um dos chips é ligado à placa Arduino, que por sua vez o alimenta e libera o áudio conforme o sensor do chip capta a radiação, e um Mpз Player com o áudio de conversas gravadas e saídas de som amplificadas, audíveis conforme a programação do Arduino. Assim, quando a radiação eletromagnética é detectada, o chip-mestre acende e torna as conversas - como ruídos pouco reconhecíveis - audíveis. Grampo contou com a colaboração da dupla de artistas Luciana Ohira e Sergio Bonilha na concepção técnica do trabalho.

O trabalho foi inicialmente apresentado na exposição 27 Formas, realizada em 2007 no Paço das Artes em São Paulo, sob a organização de Silvia Laurentiz e do Departamento de Artes Plásticas da Escola de Comunicações e Artes da Universidade de São Paulo. Mais tarde, apresentou-se também no evento Campus Party Brasil 2008, dentro da mostra Campus Futuro/Mobilefest, juntamente com o trabalho Roaming.

Uma das inspirações de Grampo na discussão social é o Reflexionismo do artista canadense Steve Mann em um outro contexto. Mann realiza ações a partir de espaços de vigilância (tais como shoppings e cassinos), utilizando-se do seu computador vestível (wearable computer) dotado de um olho-câmera e/ou conexão web para capturar em vídeo aqueles mesmos que se utilizam dos equipamentos de vigilância. Essas imagens são tornadas públicas, invertendo a situação. Não há uma apropriação dos meios propriamente, mas de suas estratégias. O Reflexionismo é colocado pelo artista como uma nova proposta filosófica e tática que toma a metodologia tradicionalmente situacionista de apropriação das estratégias do opressor como primeiro passo para avançar mirando, com a mesma metodologia, diretamente contra quem oprime (MANN, 1997).

Os falantes pertubadores do trabalho são exemplares de uma leva de pessoas que não percebem os limites entre o público e o privado ou os códigos tácitos de conduta em alguns espaços sociais. Todos aqueles que se locomovem pelas grandes cidades já se deparam diversas vezes com entusiasmados falantes que relatam pormenores íntimos ou põem-se a falar mal de alguém, sem que se respeite o direito dos demais de não compartilhar da-
5. Arduino é um projeto de hardware baseado em um simples microprocessador de código aberto, o que possibilita seu uso e produção sem limitações de licenças. O Arduino pode ser utilizado com uma infinidade de sensores, softwares ou motores, gerenciando sistemas. 
quelas palavras. Ao contrário de uma conversa em que o interlocutor está fisicamente presente no espaço, ao utilizar o celular, a presença dos outros é minimizada e, por vezes, esquecida. Então, o trabalho Grampo se propõe a atuar poeticamente em resposta ao uso do celular, gerando ruído com as mesmas conversas intrusivas - voltando-se ao celular com seus próprios resultados.

Seguindo as proposições iniciadas por Grampo, foi também desenvolvido o trabalho Captas que leva as questões do objeto anterior a campo: trata-se de dispositivos vestíveis sensíveis à radiação eletromagnética, que respondem às emissões com o ruído de conversas intrusivas e operam diretamente no espaço público. Performers no interior destas roupas atuam diretamente com os transeuntes imersos em suas conversas. Captas foi apresentado no Mobilefest - Festival de Arte e Criatividade Móvel 2009, em São Paulo e contou com duas performances em espaços urbanos até agora realizadas: uma na cidade de Natal e outra, em São Paulo. O projeto conta com o apoio da Fundação de Apoio à Pesquisa do Rio Grande do Norte (FAPERN), permitindo atualmente a realização de alguns aperfeiçoamentos na estrutura original do trabalho.

Captas pretende aprofundar as questões de invisibilidade e intromissão até aqui discutidas, desvelando ao mesmo tempo, tanto o corpo fantasmagórico da radiação eletromagnética quanto o espírito conturbado das inconveniências sociais dos telefones celulares.

\section{Referências bibliográficas}

ACKERMANN, Luciana. Ligações Perigosas: estudo diz que a radiação emitida por telefones celulares pode causar desde câncer até catarata. Isto é. São Paulo, o7 fev. 2001. Disponível em: <http://www.terra.com.br/istoe/Reportagens/fantasma_cel. htm>. Acesso em 03 de abril de 2009.

BAUMAN, Zygmunt. Amor líquido: sobre a fragilidade dos laços humanos. Rio de Janeiro: Jorge Zahar Editor, 2004. 192p.

BEIGUELMAN, Giselle. Link-se - arte/ mídia/ política/ cibercultura. São Paulo: Peirópolis, 2005. 176p.

INFORMATIONLAB. Cell Phone Disco. Disponível em: <http:// www.cellphonedisco.org >. Acesso em 10 de abril de 2009.

DE SOUZA E SILVA, Adriana. Arte e Tecnologias Móveis: Hibri- 
dizando Espaços Públicos in PARENTE, André (org.) Tramas da Rede. Porto Alegre: Sulina, 2004.

ESCOLA SUPERIOR DO MINISTÉRIO PÚBLICO DE SÃO PAULO. Caderno Jurídico: Poluição Eletromagnética. São Paulo: ESMP/Imprensa Oficial do Estado de São Paulo, 2004. 288p.

IDEO; JONES, Crispin. Social Mobiles. Disponível em: <http:// www.ideo.com/case_studies/social_mobiles/>. Acesso em 09 de julho de 2008.

NUNES, Fabio Oliveira. $C T R L+A R T+D E L$ : Distúrbios em arte e tecnologia. São Paulo: Perspectiva, 2010.

MANN, Steven. "Reflectionism" and "diffusionism": new tactics for deconstructing the video surveillance superhighway. Toronto: University of Toronto, 1997. Disponível em <http://hi.eecg. toronto.edu/leonardo/>. Acesso em og de março de 2009.

\section{FABIO FON (FÁBIO OLIVEIRA NUNES)}

É doutor em artes na Universidade de São Paulo (USP) e mestre em multimeios na Universidade Estadual de Campinas (UNICAMP). Desde 1999, desenvolve projetos de web arte e poesia digital na rede Internet. Atualmente, é pesquisador do Matizes - Grupo de Pesquisa em Cultura Visual e Docente em Arte e Tecnologia na Universidade Federal do Rio Grande do Norte (UFRN).

Site pessoal: http://www.fabiofon.com

E-mail: fabiofon@gmail.com

\section{SORAYA BRAZ}

É artista multimídia, bacharel em artes plásticas na Escola de Comunicações e Artes da USP e pesquisadora sobre a produção artística em novos meios. Atualmente, é colaboradora do Matizes - Grupo de Pesquisa em Cultura Visual da UFRN. Participou de diversos eventos em arte e tecnologia como Mobilefest 2007, FILE São Paulo 2008, Campus Party 2008 e FILE RIO 2009.

E-mail: sorayabraz@gmail.com 